\title{
Growth in the first two years of uninfected children born to HIV-1 seropositive mothers
}

\author{
C Agostoni, G V Zuccotti, M Giovannini, S Decarlis, M L Giannì, E Piacentini, \\ E D'Auria, E Riva
}

\begin{abstract}
Objective-To assess the growth curves of uninfected infants born to type 1 human immunodeficiency virus (HIV-1) seropositive mothers by means of standardised anthropometric indices.

Methods-The $\mathrm{z}$ scores (National Center for Health Statistics-World Health Organisation data) of weight for age, length for age, and weight for length of 92 uninfected full term infants born to HIV positive mothers were compared with those of 65 bottle fed full term infants born to healthy mothers at $0,1,2,3,4,6,9,12$, 18, and (in a subgroup) 24 months of age. Confounders were also recorded.

Results-The study population had a lower length for age $z$ score at birth $(95 \%$ confidence intervals $(C I): 0.02,-0.58)$ and higher weight for length $\mathrm{z}$ scores at $\mathbf{1} \mathbf{( 9 5 \%}$ CI: 0.21, 0.63), 2 (95\% CI: 0.25, 0.66), and 3 (95\% CI: $0.0,0.48)$ months compared with the reference group. After a temporary recovery, the length for age $z$ score difference increased progressively from the 4 th month onwards and was significant at 18 (95\% CI: $-0.31,-1.05)$ and 24 (95\% CI: $-0.02,-0.91$ ) months. The difference between the length for age $z$ scores at birth was associated with maternal covariates, but the between group difference at 18 months was apparent even after adjustment for covariates.

Conclusion-Uninfected infants born to HIV positive mothers have a rapid weight gain immediately after birth. A decrease in length progression during the second year might be a result of the social risk connected with the family environment and an unfavourable programming related to the maternal HIV status. (Arch Dis Child 1998;79:175-178)
\end{abstract}

Department of

Paediatrics, San Paolo Hospital, University of Milan, 8 Via A di Rudinì, 20142 Milano, Italy

C Agostoni

G V Zuccotti

M Giovannini

$S$ Decarlis

M L Giannì

E Piacentini

E D'Auria

E Riva

Correspondence to:

Dr Agostoni.

e-mail: agostoc@mbox.vol.it

Accepted 28 January 1998 Uninfected infants born to type 1 human immunodeficiency virus (HIV-1) seropositive mothers have often served as controls for their HIV infected counterparts in follow up studies ${ }^{12}$ that have used the international normative reference $\mathrm{z}$ score indices of the World Health Organisation. ${ }^{3}$

Whereas infection with HIV is associated with significant decrements across all standardised growth outcome measures after adjustment for confounders (maternal history and clinical status), ${ }^{1} \mathrm{HIV}$ uninfected infants do not show depressed weight for age or weight for length $\mathrm{z}$ scores at birth, although length for age values are lower. ${ }^{12}$ Weight for age and weight for length values increase in the HIV uninfected population immediately after birth, ${ }^{12}$ while length for age $\mathrm{z}$ score values show a persisting negative trend, even during the second year. ${ }^{2}$

To our knowledge no data are available on the early growth patterns of HIV uninfected subjects compared with infants born to healthy mothers from the same racial background. Because it has been shown that breast and formula fed infants have different growth patterns in the first two years of life, ${ }^{4}$ a local reference population should be made up of children with a similar diet. In Western countries such a population would comprise infants fed exclusively on formula, because HIV positive mothers are advised not to breast feed. ${ }^{5}$

In this study, we have analysed the standardised growth curves from a population of uninfected infants born to HIV positive mothers during a 10 year follow up period in our centre and compared them with those from a reference population.

\section{Methods}

SUBJECTS

We analysed data recorded on all infants born to HIV positive mothers since 1985 in the paediatric department, San Paolo Hospital, Milan, Italy and prospectively followed up from birth. Data were restricted to infants born at term before 1 January 1996. Maternal HIV infection and the infants' HIV negative status were documented and classified as defined by the documents from the Centers for Disease Control and Prevention over the years. ${ }^{6-8}$ Accordingly, the diagnostic schedule provided clinical and serological controls up to 18 months of age. Parents had been highly motivated to take their children for the scheduled visits, even in the case of intercurrent infection, which could be relevant to the diagnostic follow up. A subgroup was still measured at 24 months.

The reference group included all the healthy infants born at term in our maternity ward in the period between September 1992 and August 1993 whose mothers agreed to be included and were not breast feeding. Their growth indices were followed up to 24 months of age. Only mothers that did not suffer from any metabolic or infectious diseases and whose infants had an Apgar score $>7$ at five minutes were included in the study.

Informed consent was obtained from the infants' parents and the study design was 
Table 1 Infants' characteristics at birth

\begin{tabular}{lllll}
\hline & $\begin{array}{l}\text { HIV uninfected } \\
(n=92)\end{array}$ & $\begin{array}{l}\text { Reference } \\
(n=65)\end{array}$ & Mean A (SE) & p value \\
\hline Mean (SD) gestational age (weeks) & $39.2(1.3)$ & $39.2(1.4)$ & $-0.01(0.22)$ & 0.93 \\
Mean (SD) weight for age z score & $-0.29(1.16)$ & $-0.03(1.03)$ & $-0.26(0.18)$ & 0.14 \\
Mean (SD) length for age z score & $-0.31(0.96)$ & $-0.04(0.92)$ & $-0.27(0.15)$ & 0.07 \\
Mean (SD) weight for length z score & $-0.42(0.80)$ & $-0.35(0.58)$ & $-0.07(0.13)$ & 0.58 \\
Sex (M/F) & $53 / 39$ & $35 / 30$ & & 0.63 \\
Parity (1st/> 1st) & $72 / 20$ & $42 / 23$ & & 0.05 \\
\hline
\end{tabular}

Mean (SE) differences of continuous variables $(\Delta)$ between the HIV uninfected and the reference groups (SE of $95 \% \mathrm{CI}$ ).

*Weight for length $\mathrm{z}$ scores at birth have been calculated for $66 \mathrm{HIV}$ uninfected cases and 45 reference cases as standardised data were unavailable for lengths $<49 \mathrm{~cm}$.

Table 2 Parents'characteristics

\begin{tabular}{llllr}
\hline & $\begin{array}{l}\text { HIV uninfected } \\
(n=92)\end{array}$ & $\begin{array}{l}\text { Reference } \\
(n=65)\end{array}$ & Mean $\Delta(S E)$ & p value \\
\hline Father's & & & & \\
$\quad$ Mean (SD) age (years) & $30.8(5.2)$ & $34.4(5.1)$ & $-3.58(0.84)$ & $<0.001$ \\
$\quad$ Income (lower/higher) & $45 / 47$ & $18 / 47$ & & 0.007 \\
Mother's & & & & \\
$\quad$ Mean (SD) age (years) & $27.0(4.0)$ & $32.5(5.4)$ & $-5.51(0.76)$ & $<0.001$ \\
$\quad$ Education ( $\leqslant 14$ years/> 14 years) & $52 / 40$ & $23 / 42$ & & 0.009 \\
$\quad$ Smoking in pregnancy (yes/no) & $17 / 75$ & $3 / 62$ & & 0.010 \\
Drug addiction in pregnancy (yes/no) & $20 / 72$ & $0 / 65$ & & $<0.001$ \\
\hline
\end{tabular}

Mean (SE) differences of continuous variables $(\Delta)$ between the HIV uninfected and the reference groups (SE of $95 \% \mathrm{CI}$ ).

approved by the departmental ethics committee.

Both the HIV uninfected group and the reference group used standard infant formulas available in Italy, whose composition followed the recommendations issued by the European Society of Gastroenterology and Nutrition. ${ }^{9}$ Both groups were given the same schedules for the introduction of solid foods after the fourth month of life.

COLLECTION OF DATA

Subjects were examined at birth and at 1, 2, 3, $4,6,9,12,18$, and 24 months of age by trained examiners. The permissible intervals around the actual chronological age for nominal age visits were: within \pm 1 week for the first 4 months and within \pm 2 weeks for all subsequent visits. Serial weight and recumbent length were obtained by means of standard anthropometric techniques and equipment. The naked child was weighed on an electronic Sartorius scale accurate to $\pm 5 \mathrm{~g}$. Crown-heel length was measured on a portable measuring board.

Actual chronological decimal age was used to calculate the standardised $\mathrm{z}$ score anthropometric indices. The $\mathrm{z}$ scores represent the distance in standard deviations (SD) from the National Center for Health Statistics-World
Health Organisation normative reference medians for age and sex. ${ }^{10}$ The weight for age, length for age, and weight for length values were calculated by means of the ANTHRO pediatric anthropometry software program (version 1.01, Atlanta, Centers for Disease Control and Prevention, 1990).

Gestational age ( $\geqslant 37$ completed weeks) was based on the last menstruation date and confirmed by an ultrasound examination performed within the 20th week.

Parental age and parity status of infants were recorded at birth. The expected income on the basis of the father's work was coded according to the Italian Census.

Maternal education, use of drugs (opiates and cocaine), smoking habits, and alcohol intake during pregnancy were assessed by trained interviewers. The presence of symptomatic infection in the HIV positive mothers was also recorded.

\section{STATISTICAL ANALYSES}

Descriptive values are reported as means and SDs for continuous variables and absolute numbers for categorical variables. Variables were compared by means of the Student's unpaired $t$ test if continuous and the $\chi^{2}$ test if categorical. For comparisons of continuous variables, mean differences between the two groups and standard errors (SE) of the 95\% confidence intervals (CI) are reported. In addition, $95 \% \mathrm{CI}$ for between group mean differences are reported in the text. Values are not approximated but truncated at the second decimal place of the computer output.

To adjust outcome measures for confounders the following covariates were considered: infants' sex and parity (first born or not), father's income (lower or higher) based on the coded type of work, maternal age $(<$ or $\geqslant 30$ years), mother's education ( $\leqslant$ or $>14$ years), maternal drug addiction and smoking habits during pregnancy, and HIV mothers' symptomatic infection. At the beginning, all covariates were tested separately in a multiple regression model including both the HIV status (uninfected versus reference) and each covariate in turn. Subsequently, all covariates significant at $\mathrm{p} \leqslant 0.10$ were included simultaneously in a single model by dropping the least significant covariate one at a time until all covariates remaining had a $\mathrm{p}$ value less than, or close to, 0.05 . In the tables with covariate analysis, $p$ values are truncated at the third decimal place.

Table 3 Unadjusted standardised anthropometrical values throughout 24 months

\begin{tabular}{|c|c|c|c|c|c|c|c|c|c|c|c|c|}
\hline \multirow[b]{2}{*}{ Month } & \multicolumn{4}{|c|}{ Weight for age $z$ scores } & \multicolumn{4}{|c|}{ Length for age $z$ scores } & \multicolumn{4}{|c|}{ Weight for length $z$ scores } \\
\hline & $\begin{array}{l}\text { HIV } \\
\text { uninfected }\end{array}$ & Reference & $\begin{array}{l}\text { Mean } \\
\Delta(S E)\end{array}$ & $p$ value & $\begin{array}{l}\text { HIV } \\
\text { uninfected }\end{array}$ & Reference & $\begin{array}{l}\text { Mean } \\
\Delta(S E)\end{array}$ & $p$ value & $\begin{array}{l}\text { HIV } \\
\text { uninfected }\end{array}$ & Reference & $\begin{array}{l}\text { Mean } \\
\Delta(S E)\end{array}$ & $p$ value \\
\hline 1 & $-0.23(0.75)$ & $-0.39(0.71)$ & $0.16(0.12)$ & 0.17 & $-0.50(0.95)$ & $-0.28(0.85)$ & $-0.21(0.14)$ & 0.14 & $0.16(0.71)$ & $-0.25(0.54)$ & $0.42(0.10)$ & $<0.001$ \\
\hline 2 & $0.07(0.74)$ & $-0.12(0.64)$ & $0.19(0.11)$ & 0.08 & $-0.40(1.03)$ & $-0.21(0.88)$ & $-0.19(0.15)$ & 0.23 & $0.52(0.64)$ & $0.06(0.64)$ & $0.45(0.10)$ & $<0.001$ \\
\hline 3 & $0.19(0.76)$ & $0.00(0.65)$ & $0.18(0.12)$ & 0.10 & $-0.26(1.12)$ & $-0.26(0.94)$ & $0.00(0.17)$ & 0.99 & $0.47(0.85)$ & $0.23(0.62)$ & $0.23(0.12)$ & 0.05 \\
\hline 4 & $0.17(0.74)$ & $0.10(0.70)$ & $0.07(0.11)$ & 0.52 & $-0.10(1.01)$ & $-0.13(0.87)$ & $0.02(0.15)$ & 0.87 & $0.23(0.86)$ & $0.17(0.56)$ & $0.06(0.12)$ & 0.61 \\
\hline 6 & $0.19(0.82)$ & $0.18(0.79)$ & $0.00(0.13)$ & 0.96 & $-0.06(0.95)$ & $0.00(0.89)$ & $-0.06(0.15)$ & 0.66 & $0.25(0.85)$ & $0.15(0.72)$ & $0.10(0.13)$ & 0.46 \\
\hline 9 & $0.11(0.91)$ & $0.27(0.98)$ & $-0.15(0.16)$ & 0.31 & $0.04(0.94)$ & $0.14(1.04)$ & $-0.10(0.16)$ & 0.54 & $0.18(0.89)$ & $0.30(0.74)$ & $-0.11(0.14)$ & 0.41 \\
\hline 12 & $0.10(1.00)$ & $0.31(1.00)$ & $-0.20(0.17)$ & 0.23 & $-0.02(0.99)$ & $0.24(1.05)$ & $-0.26(0.17)$ & 0.11 & $0.28(1.00)$ & $0.34(0.86)$ & $-0.05(0.16)$ & 0.72 \\
\hline 18 & $0.15(1.02)$ & $0.29(1.05)$ & $-0.13(0.17)$ & 0.44 & $-0.18(1.05)$ & $0.50(1.16)$ & $-0.68(0.18)$ & $<0.001$ & $0.37(1.09)$ & $0.08(0.88)$ & $0.28(0.17)$ & 0.10 \\
\hline 24 & $0.13(1.03)$ & $0.34(1.15)$ & $-0.21(0.25)$ & 0.40 & $0.13(1.10)$ & $0.59(0.91)$ & $-0.46(0.22)$ & 0.04 & $0.17(0.99)$ & $0.13(1.07)$ & $0.03(0.23)$ & 0.87 \\
\hline
\end{tabular}

Values are mean (SD).

Mean differences $(\Delta)$ between the HIV uninfected and the reference groups (SE of $95 \% \mathrm{CI}$ ). 
Table 4 Adjusted analyses of length for age $z$ score outcome at birth

\begin{tabular}{|c|c|c|c|c|}
\hline \multirow[b]{2}{*}{ Covariates } & \multicolumn{2}{|l|}{ Two covariate model } & \multicolumn{2}{|l|}{ Final model } \\
\hline & $z$ score change $(95 \%$ CI) & p value & $z$ score change $(95 \%$ CI) & $p$ value \\
\hline HIV uninfected ${ }^{\star}$ & $-0.27(0.02,-0.58)$ & 0.074 & $-0.15(0.19,-0.51)$ & 0.376 \\
\hline Male sex & $0.11(-0.18,0.42)$ & 0.439 & & \\
\hline First born & $0.11(-0.22,0.45)$ & 0.509 & & \\
\hline Lower father's income & $-0.08(0.22,-0.39)$ & 0.588 & & \\
\hline Maternal age $\geqslant 30$ years & $-0.27(0.05,-0.60)$ & 0.100 & $-0.18(0.11,-0.48)$ & 0.224 \\
\hline Mother's education $\leqslant 14$ years & $-0.19(0.10,-0.50)$ & 0.204 & & \\
\hline Maternal drug addiction in pregnancy & $-0.50(-0.04,-0.97)$ & 0.034 & $-0.49(-0.04,-0.93)$ & 0.030 \\
\hline Maternal smoking in pregnancy & $-0.49(-0.04,-0.94)$ & 0.032 & $-0.45(-0.01,-0.90)$ & 0.044 \\
\hline HIV mothers' symptomatic infection & $-0.60(0.12,-1.34)$ & 0.104 & $-0.69(0.01,-1.39)$ & 0.054 \\
\hline
\end{tabular}

Values are the estimated change in mean length for age $\mathrm{z}$ score outcome for the indicated covariate exposure category versus its complementary group. The two covariate model column gives the unadjusted effect of the HIV status (uninfected versus reference) ${ }^{\star}$ ) and the effect sizes of each covariate after adjustment only for the HIV status. The final (adjusted) model column gives the effect sizes of the two covariates with non-significant results before being dropped and the three covariates that have a $\mathrm{p}$ value less than or close to 0.05 in the final model.

All analyses were performed by means of the SPSS for Windows 5.0 statistical computer package (SPSS Inc, Chicago, Illinois, USA).

\section{Results}

We collected data from 119 term infants born to HIV positive mothers during the study period. Among them, 92 were HIV uninfected at the end of the diagnostic follow up. All these subjects underwent a clinical examination at 1 , $2,3,4,6,9$, and 12 months of age. At 18 months of age, 91 subjects were examined (one did not present as a result of family relocation). Thirty children were measured at 24 months.

As a reference group we recruited 65 infants who presented for examination at $1(n=65), 2$ $(\mathrm{n}=65), 3(\mathrm{n}=64), 4(\mathrm{n}=64), 6(\mathrm{n}=59), 9$ $(\mathrm{n}=57), 12(\mathrm{n}=56), 18(\mathrm{n}=56)$, and 24 $(n=54)$ months of age. Reasons for dropping out were family relocation, intercurrent common infants' infections, and parents' withdrawal. All members of the reference population were exclusively formula fed from birth as a result of maternal choice. During the follow up period, none of them presented with any major disorders, malabsorptive states, chronic gastrointestinal symptoms, or recurring immunoallergic reactions requiring the elimination of specific foods.

The infants' characteristics at birth are shown in table 1 , while the parental variables of the two groups are reported in table 2. Rather surprisingly, only two HIV positive mothers, whose infants presented $\mathrm{z}$ score values close to the group means at birth, reported a habitual alcohol intake during pregnancy. Therefore, this variable was not considered in the covariate analysis. Among the $92 \mathrm{HIV}$ positive mothers, 10 presented with symptomatic infection.

The unadjusted values of weight for age, length for age, and weight for length $\mathrm{z}$ scores of the two groups during the study period are reported in table 3 .

The mean weight for age and length for age $\mathrm{z}$ scores of the reference group are slightly negative in the first months and then positive from the 4th and 9th month, respectively.

Weight for age $\mathrm{z}$ scores recover rapidly in the uninfected infants, who show a trend towards higher values than the reference group in the postnatal period, particularly between 2 and 3 months of age. At 6 months of age, the values of the two groups are similar and afterwards a non-significant gap between the HIV uninfected subjects and the reference group is evident. The study population shows a lower length for age $\mathrm{z}$ score at birth $(95 \% \mathrm{CI}$ for difference: $0.02,-0.58$ ) (table 1). Length for age $\mathrm{z}$ scores reach the same values as the controls at 3 months of age, but after the 4th month the difference increases progressively, becoming significant at 18 months of age (95\% CI: $-0.31,-1.05)$. At 24 months of age, length for age $\mathrm{z}$ scores are still lower in the HIV uninfected subgroup than in the reference group (95\% CI: $-0.02,-0.91)$. With regard to the weight for length $\mathrm{z}$ scores, infants born to HIV positive mothers show higher values than the reference group at 1 (95\% CI: $0.21,0.63)$, 2 (95\% CI: $0.25,0.66$ ), and 3 (95\% CI: 0.0, $0.48)$ months of age. After the $3 \mathrm{rd}$ month, the

Table 5 Adjusted analyses of length for age z score outcome at 18 months

\begin{tabular}{|c|c|c|c|c|}
\hline \multirow[b]{2}{*}{ Covariates } & \multicolumn{2}{|l|}{ Two covariate model } & \multicolumn{2}{|l|}{ Final model } \\
\hline & $z$ score change $(95 \% C I)$ & $p$ value & $z$ score change $(95 \% C I)$ & $p$ value \\
\hline HIV uninfected ${ }^{\star}$ & $-0.61(-0.24,-0.98)$ & 0.001 & $-0.55(-0.17,-0.92)$ & 0.004 \\
\hline Male sex & $0.02(-0.34,0.38)$ & 0.900 & & \\
\hline First born & $0.55(0.14,0.95)$ & 0.008 & $0.52(0.13,0.92)$ & 0.009 \\
\hline Lower father's income & $-0.49(-0.13,-0.86)$ & 0.007 & $-0.47(-0.12,-0.82)$ & 0.009 \\
\hline Maternal age $\geqslant 30$ years & $-0.10(0.29,-0.50)$ & 0.609 & & \\
\hline Mother's education $\leqslant 14$ years & $-0.40(-0.04,-0.76)$ & 0.027 & $-0.16(0.20,-0.54)$ & 0.383 \\
\hline Maternal drug addiction in pregnancy & $-0.57(-0.02,-1.11)$ & 0.039 & $-0.50(0.01,-1.02)$ & 0.059 \\
\hline Maternal smoking in pregnancy & $0.03(-0.49,0.56)$ & 0.896 & & \\
\hline HIV mothers' symptomatic infection & $0.15(-0.70,1.00)$ & 0.729 & & \\
\hline
\end{tabular}

Values are the estimated change in mean length for age $\mathrm{z}$ score outcome for the indicated covariate exposure category versus its complementary group. The two covariate model column gives the unadjusted effect of the HIV status (uninfected versus reference) $\left.{ }^{\star}\right)$ and the effect sizes of each covariate after adjustment only for the HIV status. The final (adjusted) model column gives the effect sizes of the one covariate with non-significant results before being dropped and the four covariates that have a $p$ value less than or close to 0.05 in the final model. 
differences become less pronounced, but at 18 months a small difference is still present.

Because the major differences between the two groups at the beginning (birth) and at the end (18 months) of the follow up concern the length for age $\mathrm{z}$ score values, we performed separate analyses of covariates for the two time points. The between group difference at birth is no longer significant after adjustment for maternal drug addiction, smoking during pregnancy, and HIV positive mothers' clinical status (table 4). At 18 months of age, the difference is still significant, even after adjustment for fathers' work, parity, and maternal drug addiction during pregnancy (table 5).

\section{Discussion}

Uninfected infants born to HIV seropositive mothers grow in an unfavourable intrauterine environment, where they might suffer from exposure to maternal infection and other variables (such as the effect of maternal malnutrition, drug addiction, smoking, poor social conditions). ${ }^{3}$ After birth, they are fed artificial formulas, at least in developed countries, because of the risk of transmitting the infection through the mothers' milk, while continuing to undergo the "social risk" connected with the status of their families.

Our data suggest that the decreased length for age $\mathrm{z}$ scores seen at birth in the uninfected infants born to HIV positive mothers are mainly associated with maternal conditions (drug addiction, smoking, and clinical status) known to affect fetal growth in the uterus. ${ }^{11}$ Immediately after birth, uninfected infants show a rapid weight gain and "catch up" of body mass, as described previously. ${ }^{12}$ This is particularly true for the weight for length index and could indicate a facilitated fat mass deposition. Interestingly, the early changes of weight for age and weight for length are similar to those found in children with HIV infection in response to a nutritional intervention, during which, weight, weight for height, and fat mass increase, but height and muscle mass do not. ${ }^{11}$ Even if mothers had not been required to record precisely the quantities of milk ingested daily by their infants, our records do not indicate abnormal eating habits concerning frequency and duration of feeding and average amounts of formula supplied at each feeding. One could speculate that compensatory rebound mechanisms to increase fat stores might take place after interrupting the connection with a maternal metabolism dominated to various degrees by the "futile cycle" of nutrients typical of the HIV infection. ${ }^{12}$ Studies on the basal energy expenditure of these subjects in the first few months of life are needed to elucidate this observation.

The progressive decrease in length for age $\mathrm{z}$ score of the HIV uninfected subjects during the second year of life is connected not only with unfavourable social conditions (lower fathers' income) and maternal drug addiction in pregnancy (whose role, either directly affecting postnatal growth or as a social marker, is unclear), but also with the condition of just being born to an HIV positive mother. We could speculate that the pattern of the length for age $\mathrm{z}$ score curve might depend on either a "downregulated" programming from the intrauterine life and/or increased dietary requirements immediately after birth not sufficiently met by the standard formulas normally supplied to this population.

According with the theory of "programming", height attainment has shown associations with later disorders. ${ }^{13}$ Larger, long term follow up studies on uninfected subjects born to HIV seropositive mothers matched with local reference standards are required to investigate the later consequences of their growth in a "high risk" environment and the hypothesis of an unfavourable fetal and infant programming.

1 Moye J, Rich KC, Kalish LA, et al. Natural history of somatic growth in infants born to women infected by the human immunodeficiency virus. F Pediatr 1996;128:58-69.

2 McKinney RE, Robertson WR, the Duke Pediatric AIDS Clinical Trials Unit. Effect of human immunodeficiency virus infection on the growth of young children. $\mathcal{F}$ Pediatr 1993;123:579-82.

3 World Health Organisation Working Group. Use and interpretation of anthropometric indicators of nutritional status. Bull WHO 1986;643:929-41.

4 Dewey KG, Heinig MJ, Nommsen LA, Peerson JM, Lonnerdal B. Growth of breast-fed and formula-fed infants from 0 to 18 months: the DARLING study. Pediatrics 1992;89:1035-41.

5 Stiehm ER. Newborn factors in maternal-infant transmission of pediatric HIV-infection. $\mathcal{F}$ Nutr 1996,126(suppl): $2632-6$.

6 Centers for Disease Control. Revision of the CDC surveillance case definition for acquired immunodeficiency syndrome. Morb Mortal Wkly Rep 1987;36:1-15S.

7 Centers for Disease Control and Prevention. 1993 revised classification system for HIV infection and expanded surveillance case definition for AIDS among adolescents and adults. Morb Mortal Wkly Rep 1992;41(RR-17):1-19.

8 Centers for Disease Control and Prevention. 1994 revised classification system for human immunodeficiency virus infection in children under 13 years of age. Morb Mortal Wkly Rep 1994;43(RR-12):1-10.

9 ESPGAN Committee on Nutrition. Guidelines on infant nutrition. III. Recommendations for infant feeding. Acta Patrition. III. Recommendation

10 Hamil PVV, Drizd TA, Johnson CZ, Reed RB, Roche AF, Hamil PVV, Drizd TA, Johnson CZ, Reed RB, Roche AF,
Moore WM. Physical growth: National Center for Health Statistics percentiles. Am f Clin Nutr 1979;32:607-29.

11 Miller TL. Nutritional assessment and its clinical application in children infected with the human immunodeficiency virus [editorial]. $\mathcal{F}$ Pediatr 1996;129:633-6.

12 Miller TL. Malnutrition: metabolic changes in children, comparisons with adults. F Nutr 1996;126(suppl):2623-31.

13 Barker DJP, Osmond C, Golding J. Height and mortality in the counties of England and Wales. In: Barker DJP, ed. Fetal and infant origins of adult disease. London: BMJ Publishing Group, 1992:86-92. 